\title{
Effect of Sunny/Shady Slopes on Phases of Precipitation in China's Tianshan Mountains
}

\author{
Xuewei Fan', Hailong Liu', Xi Chen ${ }^{3}$, Ling Wang ${ }^{4}$ \\ ${ }^{1}$ College of Water Resources and Architectural Engineering, Shihezi University, Shihezi, China \\ ${ }^{2}$ School of Resources and Environment, University of Electronic Science and Technology of China, Chengdu, China \\ ${ }^{3}$ Xinjiang Institute of Ecology and Geography, Chinese Academy of Sciences, Urumqi, China \\ ${ }^{4}$ College of Architecture and Civil Environment, Xihua University, Chengdu, China
}

Received: 10 December 2017

Accepted: 10 April 2018

\begin{abstract}
Precipitation is an important element in the hydrological cycle in mountainous regions. Temporal and spatial variations in precipitation and in its two phases - rain and snow - over the northern and southern aspects of the slopes of the Tianshan Mountains are compared and analyzed using 55-year data (1961-2015). The results of the analysis are as follows:

1) The average annual precipitation shows an upward trend: rainfall on the northern slopes increase by $6.7 \mathrm{~mm}$ per decade and that on the southern slopes by $6.4 \mathrm{~mm}$ per decade; the corresponding figures for snow are $2.0 \mathrm{~mm}$ and $4.2 \mathrm{~mm}$; and the ratio of snowfall to precipitation (S/P) showed a weak decreasing trend on both the slopes.

1) At a confidence level of 0.05 , the $M-K$ test shows that rain, snow, and $S / P$ increased after the change point, while rain and snow change significantly in the proportions,but S/P does not.

2) On the northern slopes, the periodicity of major changes is 25 years for rain and 30 years for snow, whereas on the southern slopes the pattern is the exact opposite, the periodicity of major changes being 25 years for rain and 30 years for snow.
\end{abstract}

Keywords: change point, precipitation phase, Mann-Kendall test, periodicity analysis

\section{Introduction}

Even a minor change in the two phases of precipitation - rain and snow - can have a major impact on the environment as well as on people [1-2]. Globally, more than $50 \%$ of meteorological disasters are closely related to the transition phase of precipitation [3-4]. Snow greatly increases albedo, substantially altering the land surface energy budget, whereas rain has the exact

*e-mail: liuhl@uestc.edu.cn opposite effect [5]. In addition, rain data are modified depending on the phase of precipitation, because the data from a precipitation gauge are derived from rain or snow [6]. Especially in mountainous regions, precipitation is a major source that replenishes water resources; thus, different watersheds respond very differently to different phases of precipitation: during and after a rainfall event, water first seeps into the soil and then replenishes groundwater or goes away as runoff, whereas snow gets stored as snowpack until it gradually melts [7-8]. Correctly determining the phase of precipitation is thus crucial to both simulating 
hydrological processes and managing water resources rationally in the mountains. However, our present study is limited to differentiating between the two phases of precipitation by using temperature as a critical factor in hydrological modelling.

The IPCC's Fifth Assessment Report concluded that global warming over the last hundred years is beyond doubt, and that the trend to an increasingly warmer climate in China is consistent with that seen worldwide [9]. Global warming has become a major challenge for human survival because it accelerates the water cycle, exacerbates extreme hydrological events such as floods and droughts, and reduces water efficiency [10]. Rising temperatures not only lead to changes in the amount of precipitation, but also to changes in its phases, thereby changing the processes involved in the water cycle in mountainous regions [11-13]. At higher elevations in China's mountainous regions, where temperatures are markedly low, solid precipitation could account for a large part of the total volume of both runoff water and stored water [14]. The main runoff in the Tianshan Mountains comes from the thaw from higher elevations and from rainfall [15]. When rainfall increases in summer, rivers are recharged, leading to floods during summer and autumn; when snow increases in winter, the snow accumulates on the surface initially and then melts in the following spring, thereby increasing the amount of water (snowmelt) in mountain areas and contributing to the peak runoff in spring [16]. Although extreme precipitation events have been the focus of a great deal of research over the past few years, more studies are needed to investigate the characteristics and impacts of different phases of precipitation.

Past studies on the phases of precipitation have concentrated mainly on the temperature profile and geopotential thickness to explore the conditions that govern the precipitation phase [17-20] and on the microphysical aspects of the transformation between rain and snow [21-22]. Studies on the precipitation phases in the Tianshan Mountains are confined mainly to analysis of the characteristics of snow and the process of melting [23-25]: a systematic analysis of the phase transformation in the Tianshan Mountains has received little attention.

The present study seeks to fill that gap by systematic analysis, taking the Tianshan Mountains as the research region, and explores the temporal and spatial variations in the two phases of precipitation, as well as their relative proportions, by comparing the north-facing slopes and the south-facing ones. The study can further get our understanding of the impact of climate change on the phases of precipitation and on the hydrological processes and would play a decisive role in rational allocation and sustainable development of water resources in Xinjiang and Central Asia.

\section{Material and Methods}

Study Region

The Tianshan Mountains lie in northwestern China (Fig. 1), covering the entire Xinjiang region, and stretching for $1700 \mathrm{~km}$ along the east-west axis. The average elevation is $4000 \mathrm{~m}$ [26]. The mountains block large amounts of water vapour and form 'wet islands' amidst arid areas. The Tianshan Mountains are the origin of 373 rivers in Xinjiang, accounting for more than $50 \%$ of the total run-off in Xinjiang [27]. The average annual precipitation of about $410 \mathrm{~mm}$ is distributed unevenly across the Tianshan Mountains, with greater precipitation in the northern slopes and in the west than in the southern slopes and in the east. The proportion of the two phases of precipitation, solid and liquid, also varies with altitude and season [28-29].

\section{Data}

Data of daily mean temperature, precipitation, and relative humidity over a 55-year period (1961-2015) from 30 weather stations in the Tianshan Mountains were disposed from the Meteorological Administration of

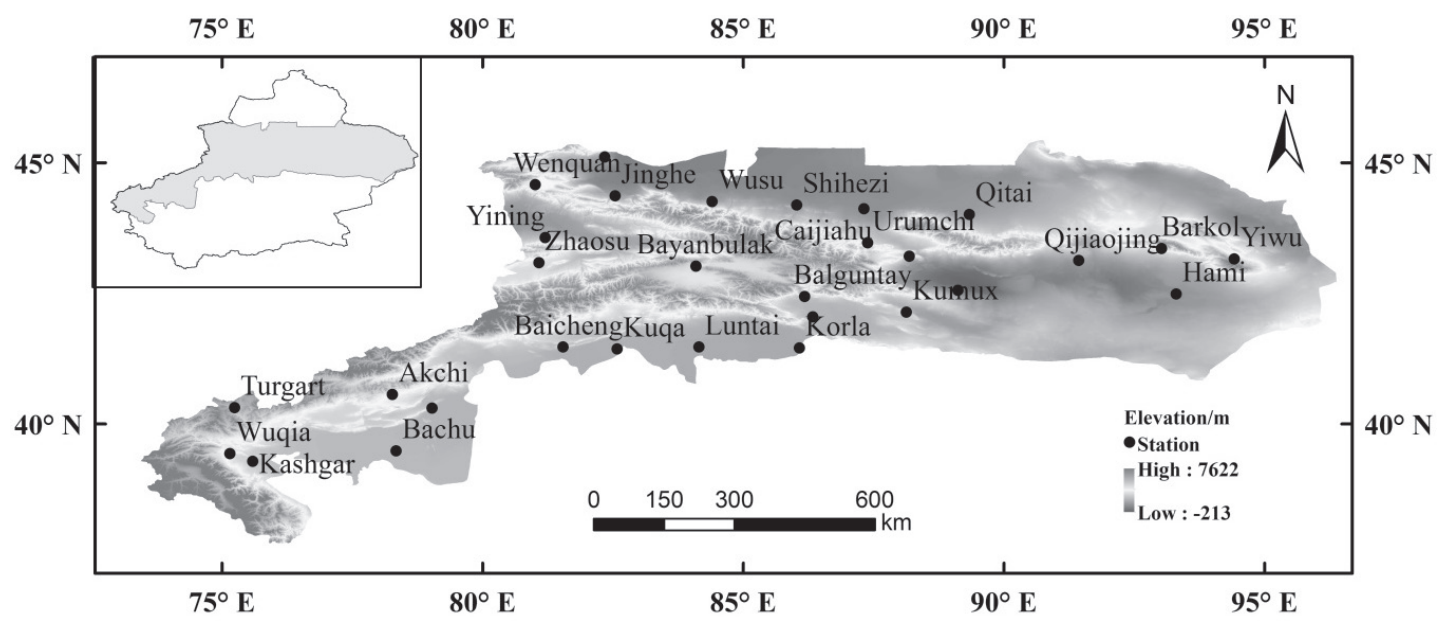

Fig. 1. Study area and distribution of meteorological stations. 
China (www.cma.gov.cn). The data passed strict qualitycontrol checks. The precipitation data for 1961-1979 include marks for the phases of precipitation.

The data from some stations (Yiwu, Dabancheng, and Shihezi) are incomplete for some years, and the gaps were filled by using correlation analysis and interpolating the data from adjacent stations for the corresponding years.

\section{Methods \\ Precipitation Trend Analysis}

The trends in precipitation were analysed using the tendency analysis method. A linear regression equation between $X$ and $t$ was established by using $X_{i}$ to represent the climate variable of time $t_{i}[30]$ :

$$
X_{i}=a+b t_{i}(\mathrm{i}=1,2, \ldots, \mathrm{n})
$$

...where $b$ is the regression coefficient (tendency rate) reflecting the trend of the variable and a is the regression constant.

To reduce random error and to eliminate noise, the moving average method was used with a 10 -year moving average to reflect the trends in precipitation. The following formula is commonly used for calculating moving averages:

$$
\overline{X_{j}}=\sum_{i=j}^{i+m-1} \frac{X_{i}}{m}
$$

...where $X j$ is the sliding average for $m$ consecutive years starting from $j$. Here, $m=10$.

\section{The Mann-Kendall Test}

The Mann-Kendall (M-K) test is a non-parametric test recommended by the World Meteorological Organization, which has been applied to trend analysis of hydro- meteorological time series [31]. The results of the M-K test are not affected by a few extreme or abnormal values; the test is, therefore, widely used especially in trend analysis and mutation testing in hydrology and meteorology. The detailed steps of the test are described by [32].

In the M-K test, the null hypothesis, $H_{0}$, is that the data in a time series $\left(x_{i}, i=1,2, \ldots, n\right)$ has seen no trend in precipitation over time. The alternative hypothesis, $H_{l}$, is that the series shows a monotonic trend. The rank sequence $S_{k}$ is constructed as follows:

$$
\begin{gathered}
S_{k}=\sum_{i=1}^{k} r_{i}(k=2,3, \ldots, n) \\
r_{i}=\left\{\begin{array}{ll}
1 & x_{i} \geq x_{j} \\
0 & x_{i}<x_{j}
\end{array} \quad j=1,2, \ldots, n\right.
\end{gathered}
$$

...and the statistical variables are defined as follows:

$$
\begin{gathered}
U F_{k}=\frac{\left[S_{k}-E\left(S_{k}\right)\right]}{\sqrt{\operatorname{var}\left(S_{k}\right)}}, k=2,3, \ldots, n \\
E\left(S_{k}\right)=\frac{k(k-1)}{4} \\
\operatorname{var}\left(S_{k}\right)=\frac{k(k-1)(2 k+5)}{72}
\end{gathered}
$$

$U F_{k}$ is the standard normal distribution; for a given level of significance $\alpha$ (generally taken $\alpha=0.05$ ), if $U F_{k}>U_{\alpha / 2}$ the original hypothesis was accepted, namely the trend is insignificant. Meanwhile, the statistics $U F_{k}$ was used to judge the extent of the time series trend. The greater $\left|U F_{k}\right|$ indicated the more remarkable changing trend (increase or decrease). The sequence of times is inverted in order to $x_{n}$, and the same operation is repeated to get $U B_{k}$ while ensuring that $U B_{k}=-U F_{k}(k=1,2, \ldots, n)$. And if the intersection of $U F_{k}$ and $U B_{k}$ was between the critical values, then the intersection point is a starting point of initial trend changing.

\section{Wavelet Analysis Periodic Test}

Wavelet analysis was used for testing periodic changes in the phase of precipitation in the study area. This is an analytical method that shows the time change of climate factors; it was later introduced into hydrology [33], and can be used for analysing local variations in time series of meteorological parameters. Based on the characteristics of hydrological data, the Morlet wavelet was selected as the wavelet function $\varphi(t)$; the constant wavelet transformation of time series $f(t)$ was defined as follows:

$W_{f}(m, n)=\int_{-\infty}^{+\infty} f(t) \varphi_{m n}^{*}(t) d t=\frac{1}{\sqrt{m}} f(t) \varphi^{*}\left(\frac{t-n}{m}\right) d t$

...where $W_{f}(m, n)$ is the wavelet transformation coefficient, $\varphi_{m n}^{*}(\mathrm{t})$ is a complex conjugate function, $m>0$ is the scale factor reflecting the length of the wavelet period, and $n$ is the time factor reflecting the translation time. Based on how $W_{f}(m, n)$ changes by $m$ and $n$, we can draw a two-dimensional contour map about $W_{f}(m, n)$, with $m$ as the ordinate and $n$ as the abscissa. This map can reflect the wavelet change characteristics of that time series and reveal its local feature on multiple timescales. $\varphi(t)$ can take different forms; the form of a Morlet wavelet transform being as follows:

$$
\varphi(\mathrm{t})=\left(1-\mathrm{t}^{2}\right) \exp \left(-\mathrm{t}^{2} / 2\right)
$$




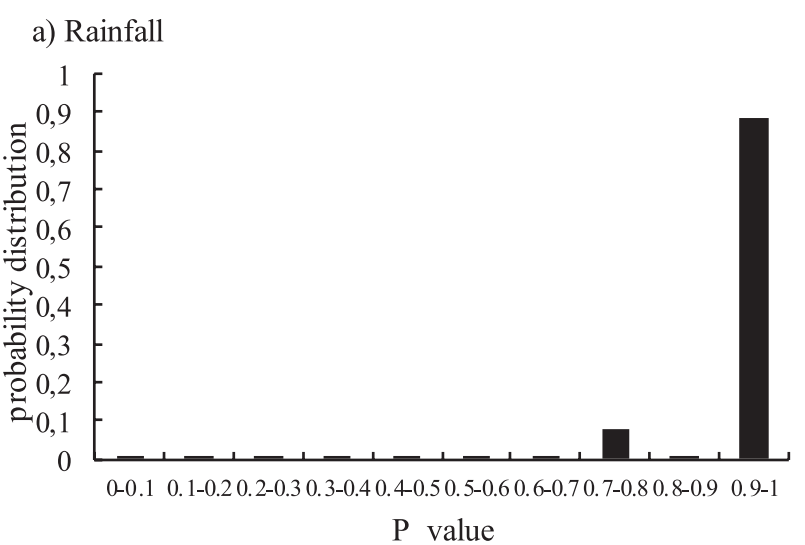

b) Snowfall

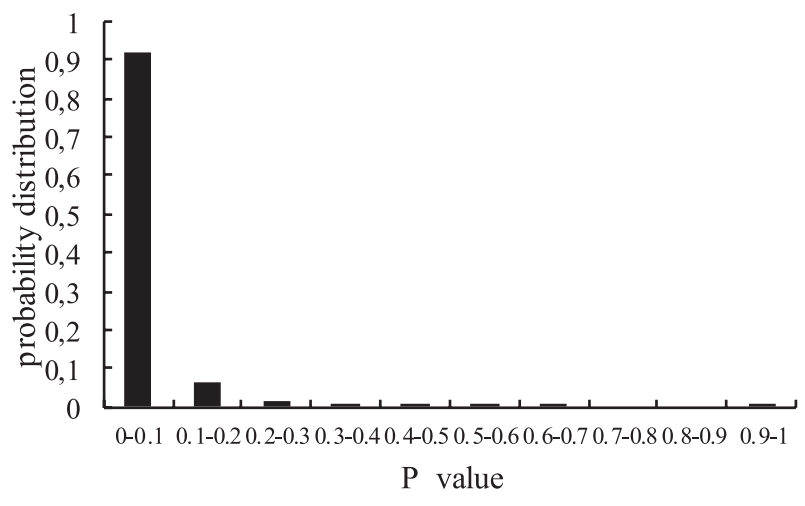

Fig. 2. Probability distribution of rain and snow for the period 1961-2015 over Tianshan Mountains.

The wavelet variance is expressed by the following formula, which can be used to determine the main period:

$$
\operatorname{var}(m)=\int_{-\infty}^{+\infty}\left|W_{f}(m, n)\right|^{2} d n
$$

\section{Determining Precipitation Phases}

The phase of precipitation depends on specific atmospheric conditions: distribution of heat and humidity, vertical motion, and the distribution of clouds and ice nuclei [34]. However, data on cloud condensation and on the distribution of ice nuclei are difficult to acquire; the easier alternative is to use relative humidity and temperature to forecast the precipitation phase. In the present paper, a method of classifying the precipitation phase was used that was based on daily mean temperature and relative humidity, as proposed by Koistinen and Saltikoff [35]:

$$
P=\frac{1}{1+e^{22-2.7 T-0.2 R H}}
$$

...where $P$ is the probability (between 0 and 1 ) of precipitation, $T$ is the daily mean temperature $\left({ }^{\circ} \mathrm{C}\right)$, and $R H$ is the daily mean relative humidity (\%). When the precipitation phase is rain, $P$ is closer to 1 ; when the precipitation phase is snow, $P$ is closer to 0 .

Based on the meteorological data for 1961-1974 (the period in which the precipitation phase was also recorded), the daily mean temperature and relative humidity data for rain were separated from those of snow; and the $P$ value was calculated from Equation 11. Finally, the range of $P$ values for the two phases was analyzed (Fig. 2).

Fig. 2 shows that when precipitation is in the form of rain, most of the $\mathrm{P}$ values are closer to 1 (between 0.7 and 1), whereas when precipitation is in the form of snow, most of the $P$ values are closer to 0 (between 0 and 0.7). Therefore, the $P$ value of 0.7 was identified as the critical value to separate the two phases of precipitation.

\section{Results and Discussion}

\section{Verifying the Criteria for Phase of Precipitation}

The phases of precipitation over the Tianshan Mountains were identified by the method described in Section Determination of precipitation phases, and the results were validated by tallying them with the data for 1975-1979, for which the phases had been recorded. The results of this comparison are shown in Table 1.

The classification of the precipitation phases into rain and snow proved reasonably accurate: rain was predicted with an accuracy of $94.6 \%$ and snow with $99.9 \%$. The overall prediction of accuracy for total precipitation was $96.3 \%$. Therefore, this prediction method is feasible. Using this method, the phases of precipitation were identified for 1980-2015 (the phases had not been recorded during this period), and temporal and spatial variations in the phases of precipitation over the northern slopes of the Tianshan Mountains were compared with those over the southern ones.

\section{Analyzing the Trends in Precipitation Phases}

Total annual precipitation over the 55-year period (1961-2015) was divided into its two phases, namely

Table 1. Validation of the precipitation phase as identified by a critical value.

\begin{tabular}{|c|c|c|c|}
\hline Phase of precipitation & Forecast errors & Total number of forecast & Predict on accuracy (\%) \\
\hline Rain & 265 & 4858 & 94.6 \\
\hline Snow & 33 & 3299 & 99.9 \\
\hline Precipitation & 298 & 8157 & 96.3 \\
\hline
\end{tabular}


rain (Fig. 3a) and snow (Fig. 3b), and the proportion of snow in the total precipitation ( $\mathrm{S} / \mathrm{P}$ ratio, Fig. $3 \mathrm{c})$ are shown separately for the northern slopes (Fig. 3, left) and the southern slopes (Fig. 3, right).

Fig. 3 shows that during the 55 years, although precipitation from both phases (rain and snow) increased over the Tianshan Mountains, the increase in the northern slopes was greater than in the southern ones (the increase in each case was significant at the 0.05 level). The rate of increase in rainfall over the southern slopes $(6.73 \mathrm{~mm}$ per decade) was slightly greater than that over the northern slopes $(6.41 \mathrm{~mm}$ per decade).
Maybe the water vapour from the Indian Ocean and Western Pacific Ocean has become stronger in southern Xinjiang since the 1980s, which caused a rain increase [36]. The 10-year moving average shows a synergistic inter-annual variation in rainfall between the northern and the southern slopes: an increasing trend after the middle of the $1980 \mathrm{~s}$ period. This is consistent with a previous study [37]. As winter temperatures in the northern slopes are higher than those in the southern ones and snow is formed only at temperatures below $0^{\circ} \mathrm{C}$, the rate of increase in annual snowfall over the northern slopes (4.26 $\mathrm{mm}$ per decade) is greater than
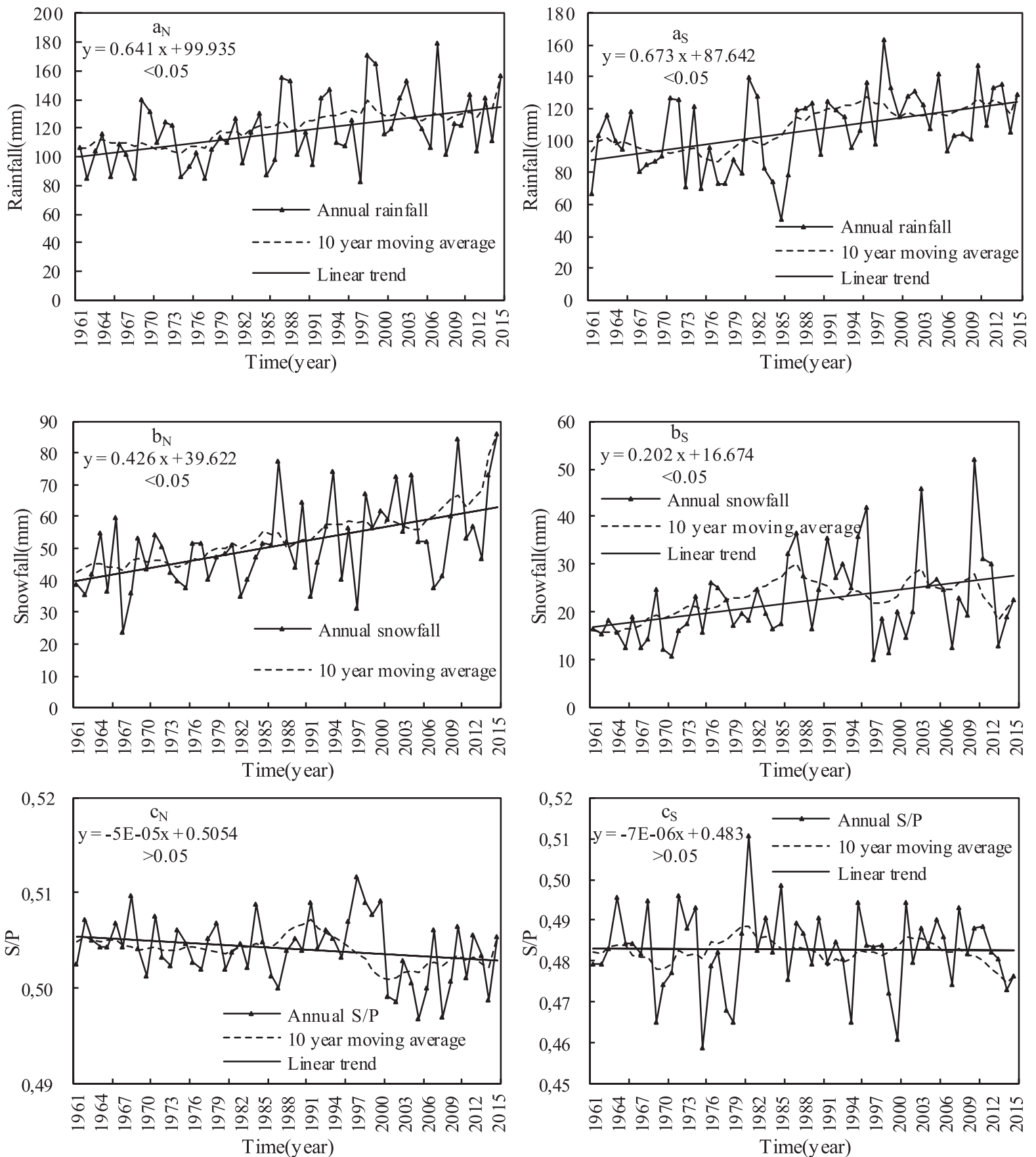

Fig. 3. Temporal variations in the precipitation phases and proportion of snow in the total precipitation (S/P ratio) in the northern and southern slopes of Tianshan Mountains (a: rain, b: snow, c: S/P ratio, N: northern slopes, S: southern slopes) for the period 1961-2015. 
that over the southern slopes (2.02 $\mathrm{mm}$ per decade). The 10-year moving average shows the upward trend in snowfall in the northern slopes over 55 years. Although the rate of change in annual rainfall in the southern slopes was greater before 1985 and decreased thereafter, the average snowfall after 1985 was generally above average. The snowfall-to-precipitation ratio in the northern slopes was greater than 0.5 , whereas that in the southern slopes was between 0.45 and 0.50 . The ratio showed a slight downward trend in both slopes, but the change was not significant at the 0.05 level. The decrease in the proportion of snow in total precipitation, although slight, will affect the seasonal distribution of run-off in the Tianshan Mountains - a conclusion that is in agreement with that of Guo et al. [38]. The probable cause is the rising temperature in the Tianshan Mountains as a result of climate change [39]. The 10-year moving average of $\mathrm{S} / \mathrm{P}$ showed the following changes: the proportion of snow in the northern slopes changed little before 1985 but increased thereafter until 1990, decreased again, although slightly, until 2000, only to increase again thereafter; the proportion of snow during this period (1961-2015) was the smallest in 55 years. The proportion of snow in the southern slopes increased during 1961-1964 and 1971-1980, but decreased during
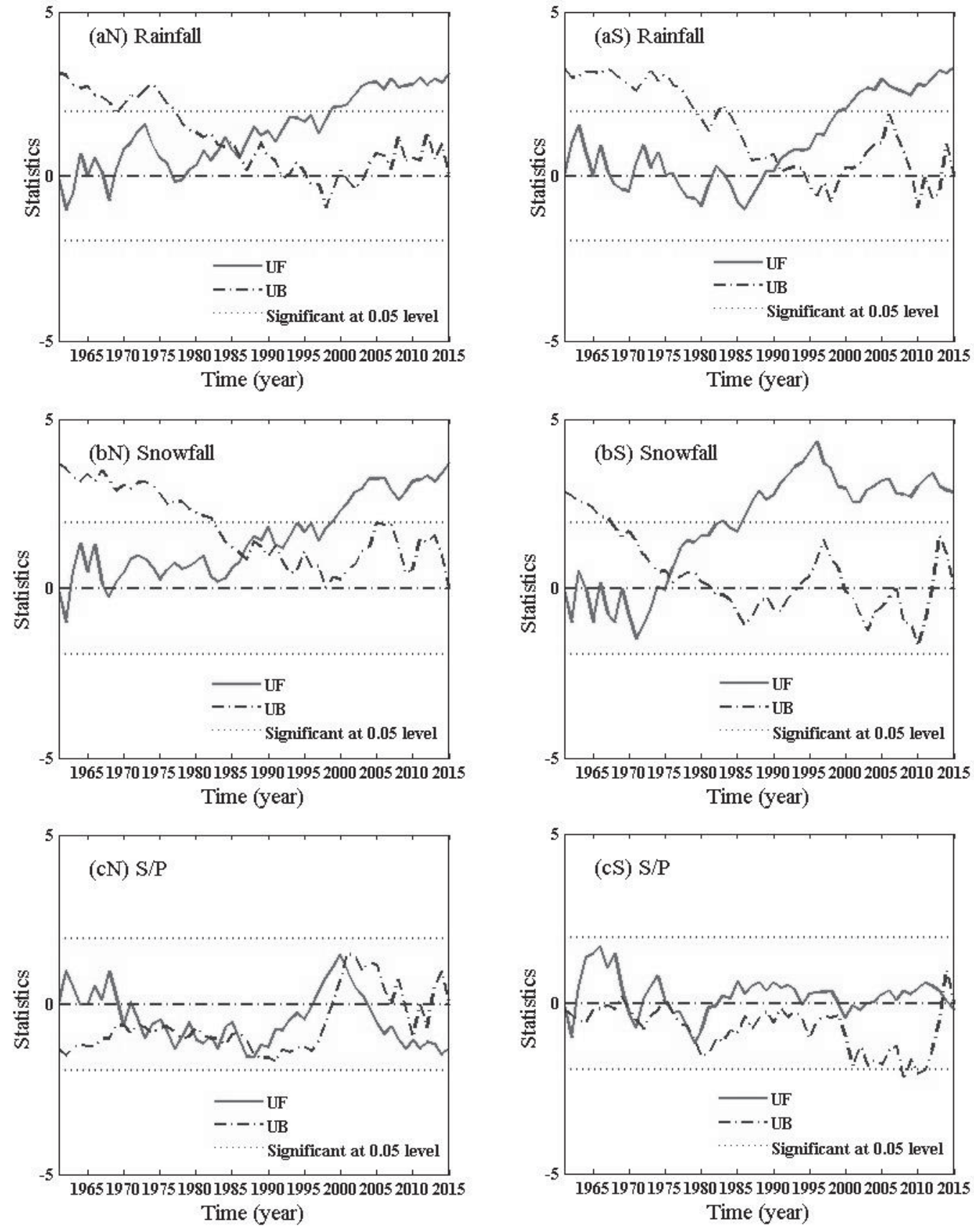

Fig. 4. Results of the Mann-Kendall test for rain, snow, and the proportion of snow in the total precipitation (S/P ratio) in the northern and southern slopes of the Tianshan Mountains (a: rain, b: snow, c: S/P ratio, N: northern slopes, S: southern slopes). 
1964-1970 and 1981-1990; after 1990, the change was smoother.

\section{Analysis of Mutation Variations in the Precipitation Phases}

The rain, snow, and S/P time series were tested by the $\mathrm{M}-\mathrm{K}$ method to examine the trends in the phases of precipitation and their change point (Fig. 4).

Fig. 4 shows that the fluctuations in rainfall (the UF curve) in the northern slopes of the Tianshan Mountains were greater before 1977: after 1977, the UF curve is wavy and shows an upward trend, and its value is always greater than 0 ; the pattern for the southern slopes is similar, but 1990 appears to be a threshold year. Rainfall increased markedly after 1985 in the northern slopes and after 1990 in the southern slopes. At a confidence level of 0.05 , rainfall in the northern slopes recorded a mutation change of about 1985 - an increase of $20.9 \mathrm{~mm}$ after the mutation, whereas rainfall in the southern slopes shows a mutation change about 1990, an increase of $24.1 \mathrm{~mm}$ after the mutation. Thus the mutational difference for the southern slopes was greater than that for the northern ones. After the mutation, the UF curve exceeds the significant level of 0.05 after 2000, indicating that rainfall of both northern and southern slopes increased significantly.

Snowfall in the northern slopes fluctuated gently during 1961-1968. After 1969, the UF curve continued to increase, and its value was greater than 0 , indicating that snowfall increased in the northern slopes after 1969, and increased significantly after 2000 because the UF curve of the northern slopes exceeds the significance level of 0.05 . The snowfall in the southern slopes continued to increase during 1975-1995 and the value of the UF curve shows a slight decrease after 1995; however, the value is always greater than 0 , which means that snowfall increased during 1975-2015. The snowfall in the northern slopes recorded a mutation change about 1986 - an increase of $12.7 \mathrm{~mm}$ after the mutation, whereas the snowfall in the southern slopes recorded a mutation change about 1976, a $7.4 \mathrm{~mm}$ increase after the mutation, and the UF curve of the southern slopes exceeds the significant level of 0.05 after 1987, indicating that snowfall increased markedly after this time point. The mutational difference in the northern slopes was greater than in the southern ones. The $\mathrm{S} / \mathrm{P}$, as seen in the UF curves for the northern and southern slopes, always fluctuated around 0 , and the mutation change is not conspicuous. The curve for the northern slopes shows many cut-off points during 1970-1990, indicating complicated transitions in the phases of precipitation. Another cut-off point for the northern slopes is seen in 2000, with the mutation value of a decrease in snowfall being 0.003 , indicating that snowfall had begun to decrease. The value of the UF curve for $\mathrm{S} / \mathrm{P}$ for the southern slopes was more than 0 before 1969, showing that the snowfall increased during that period; after 1969, however, no significant mutation is seen: the value of the UF curve kept fluctuating around 0 .
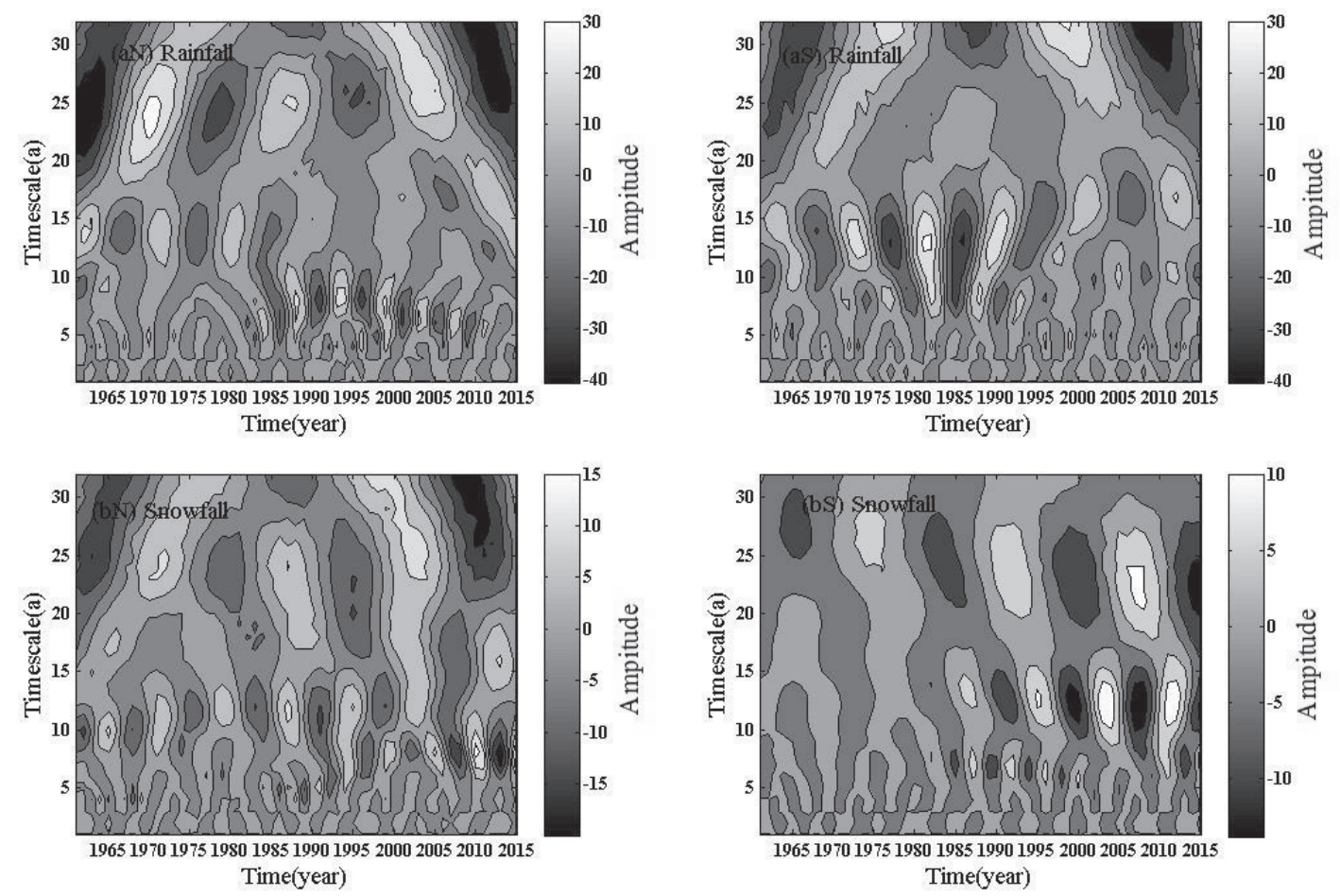

Fig. 5. Periodic variations in rainfall and snowfall in the northern and southern slopes of Tianshan Mountains (a: rain, b: snow, c: S/P ratio, N: northern slopes, S: southern slopes) for the period 1961-2015. 


\section{Periodic Variations in the Precipitation Phase}

To understand the periodic variations in the phases of precipitation, the time series of rainfall, snowfall, and $\mathrm{S} / \mathrm{P}$ were analyzed by the wavelet method, and the results are shown in Fig. 5 (periodic variations) and Fig. 6 (variance of the periodic variations).

Fig. 5 shows the periodic oscillations in the phases of precipitation on different timescales in the northern and southern slopes of the Tianshan Mountains. The northern slopes show variations in rainfall with periodicities of 8,15 , and 25 years. The periodicity of oscillation in rainfall was 15 years before 1985 , and a significant oscillation with a periodicity of 8 years is seen after 1985 . The strongest signal is seen with a periodicity of about 25 years, and the periodic oscillation shows 3.5 cycles of alternation between the minus (-) and the plus ( + ) phases. The southern slopes show variations in rainfall with periodicities of 3, 8, 15, and 30 years, the strongest signal being that with the periodicity of oscillation of about 30 years; the periodic oscillation shows 2.5 cycles of alternation between the minus and the plus phases. The northern slopes show a periodicity of 16 years for snowfall mainly since 2000 , which changed to that of about 8 years thereafter. Snowfall in the southern slopes shows periodicities of 8 years, 12 years, and 25 years, the signal for the 25 -year cycle being the strongest. The periodic oscillation of snowfall shows 3.5 cycles of alternation between the minus and the plus phases. The 8 -year cycle occurred mainly after 1985 .

The major period of precipitation in the northern and southern slopes of the Tianshan Mountains can be obtained using wavelet variance (Fig. 6). In the northern slopes, the rain had a 25 -year principal period and snow was 30 years; in the southern slopes, the corresponding values were the other way round, at 30 years for rain and 25 years for snow. On the whole, the contour of the negative phase of the rainfall wavelet coefficients in both northern and southern slopes was closed, indicating that rainfall in both slopes will be more than normal under the principal period after 2015. The contour of the negative phase of the snowfall wavelet coefficient was closed in the northern slope, whereas that in the southern slopes is yet to be closed under the principal period. In other words, snowfall in the northern slopes is likely to continue being normal, whereas that in the southern slopes will continue to be less than normal over the next 20-30 years. Therefore, the S/P ratio in the southern slopes will continue to decline over the next 20 years, whereas the future ratio in the northern slopes needs further exploration.

\section{Trend in the Spatial Variation of the Precipitation Phases}

The spatial distribution of the annual average rainfall and snowfall among the 30 meteorological stations in
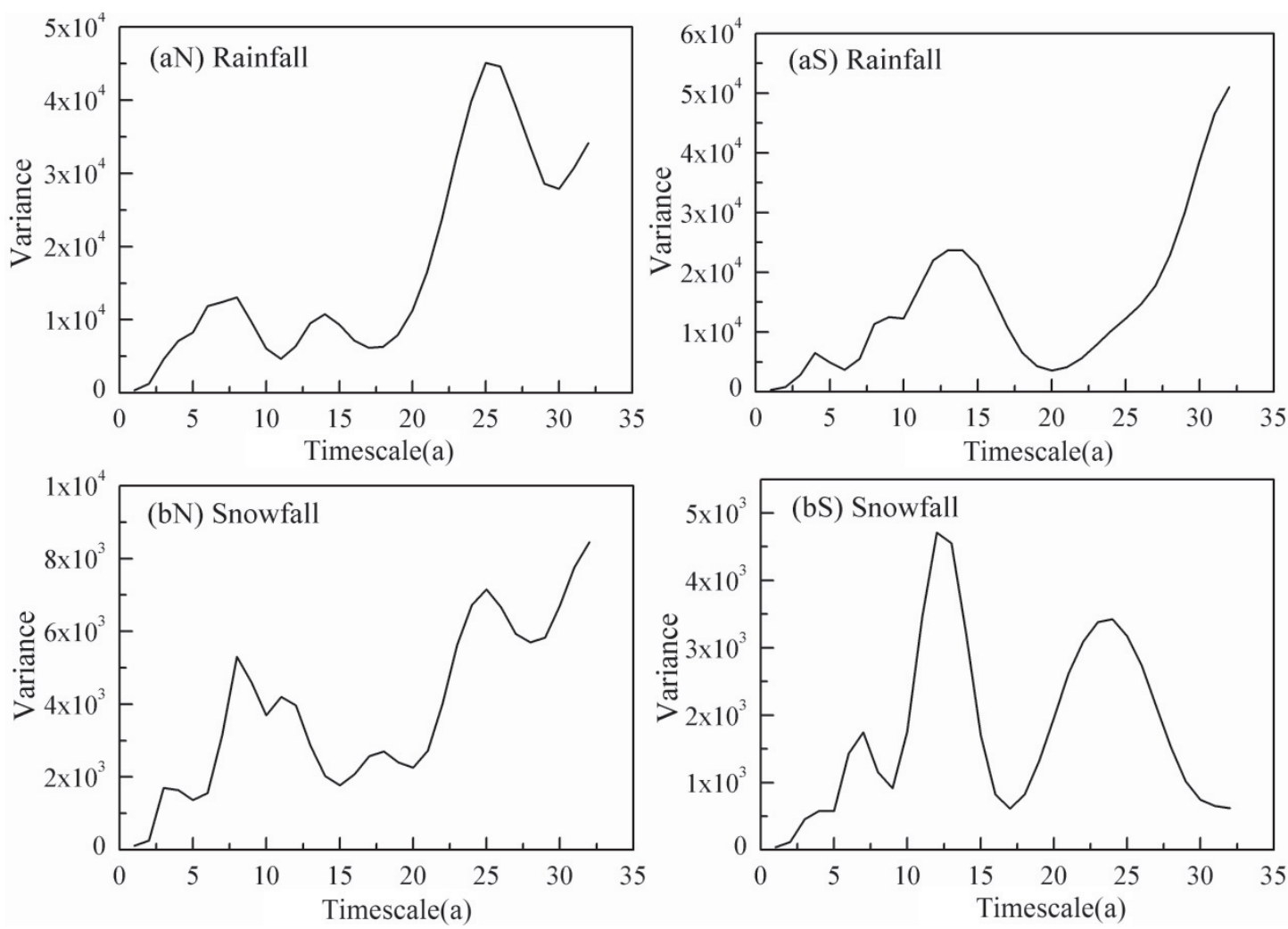

Fig. 6. Variance of periodic variations in rainfall and snowfall in the northern and southern slopes of Tianshan Mountains (a: rain, b: snow, c: S/P ratio, N: northern slopes, S: southern slopes). 


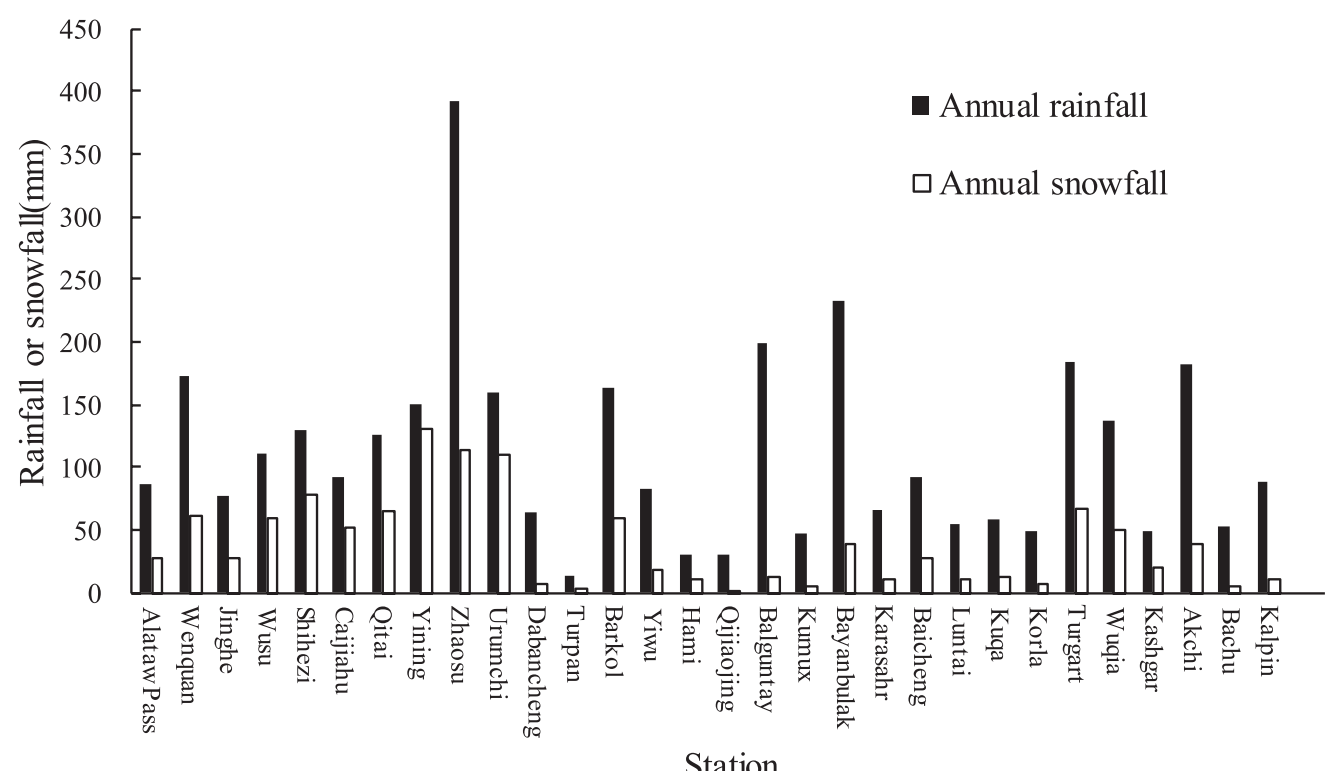

Fig. 7. Spatial distribution of annual total rainfall and snowfall in northern and southern slopes of Tianshan Mountains for the period 1961-2015.

the Tianshan Mountains is shown in Fig. 7 (the first 16 stations are located along the northern slopes and the rest along the southern slopes).

The westerly circulation is the main source of precipitation in the Tianshan Mountains [40]. The northern slopes of the Tianshan Mountains are windward and face the flow of moist air, whereas the southern slopes are leeward. Therefore, the northern slopes receive significantly greater precipitation than the southern ones. Because the moist air carried by the westerly circulation is pushed upwards by the terrain, the Yili and Zhaosu counties on the northern slopes receive abundant precipitation: the annual maximum rainfall and snowfall during the 55 years are $390.5 \mathrm{~mm}$ and $129.5 \mathrm{~mm}$, respectively. On the other hand, Turpan and Hami counties, although along the northern slopes, are arid: the minimum annual rainfall and snowfall are $12.4 \mathrm{~mm}$ and $1.5 \mathrm{~mm}$, respectively, because both are far away from the sea and the Tianshan Mountains block the flow of humid air. The southern slopes had two locations of high precipitation, namely Bayinbuluk Station (annual maximum rainfall of $232.9 \mathrm{~mm}$ ) and Turgart Station (annual maximum rainfall of $183.8 \mathrm{~mm}$ ): Bayinbuluk lies in the middle of the southern slopes and Turgart is on the western edge (see Fig. 1). The more arid places along the southern slopes are Kumish, Korla, Kashi, and the surrounding area, with minimum annual precipitation of $47.5 \mathrm{~mm}$. Overall, the annual snowfall in the southern slopes is generally below $15 \mathrm{~mm}$ - the lowest $(5.1 \mathrm{~mm})$ being in Kumish (except Bayinbuluk, Turgart, and surrounding areas).

Annual rainfall, snowfall, and $\mathrm{S} / \mathrm{P}$ ratio were interpolated on the ArcGIS platform to plot their spatial distribution (Fig. 8).

The trend of changes in the phase of precipitation was different in different areas, but the spatial distribution of the phases was similar in both northern and southern slopes (Fig. 8). Except for Qijiaojing on the northern slopes, rainfall and snowfall increased in both slopes, although the extent of increase showed a decline from east to west. The stations that recorded higher rates of increase in both rainfall and snowfall were in the central and western parts of the northern slopes: Wenquan, at $14.2 \mathrm{~mm}$ per decade, recorded the highest rate of increase in rainfall, and Urumqi, at $13.8 \mathrm{~mm}$ per decade, for snowfall. The stations that recorded lower rates of increase in both rainfall and snowfall were in the eastern part of the northern slopes, with Qijiaojing at $-2.8 \mathrm{~mm}$ per decade (rainfall) and $-0.1 \mathrm{~mm}$ per decade (snowfall) as the only place that recorded negative growth.

In the southern slopes, stations that recorded higher rates of increase in rainfall were to the west and in the central parts of the north, with Akeqi, at $20.1 \mathrm{~mm}$ per decade, recording the highest rate; the stations that recorded lower rates of increase in rainfall were to the east and in the central part of the south region, with Karasahr, at $0.4 \mathrm{~mm}$ per decade, recording the lowest rate. Half of the stations in the northern slopes and $57 \%$ in the southern slopes showed a significant rate of increase in rainfall. The rate of increase in snowfall was generally small in the southern slopes, with Bachu in the west, at $0.3 \mathrm{~mm}$ per decade, recording the minimum value and only two, Bayinbuluk (6.5 $\mathrm{mm}$ per decade) and Turgart (5.1 $\mathrm{mm}$ per decade), recording moderately high values. With respect to snowfall, $63 \%$ of the stations in the northern slopes and only $29 \%$ of them in the southern slopes showed a significant increase in the rate, pointing to a marked tendency toward greater snowfall along the northern slopes. On the whole, the rate of increase in the $\mathrm{S} / \mathrm{P}$ ratio increased from west to east in the Tianshan Mountains, with the central 

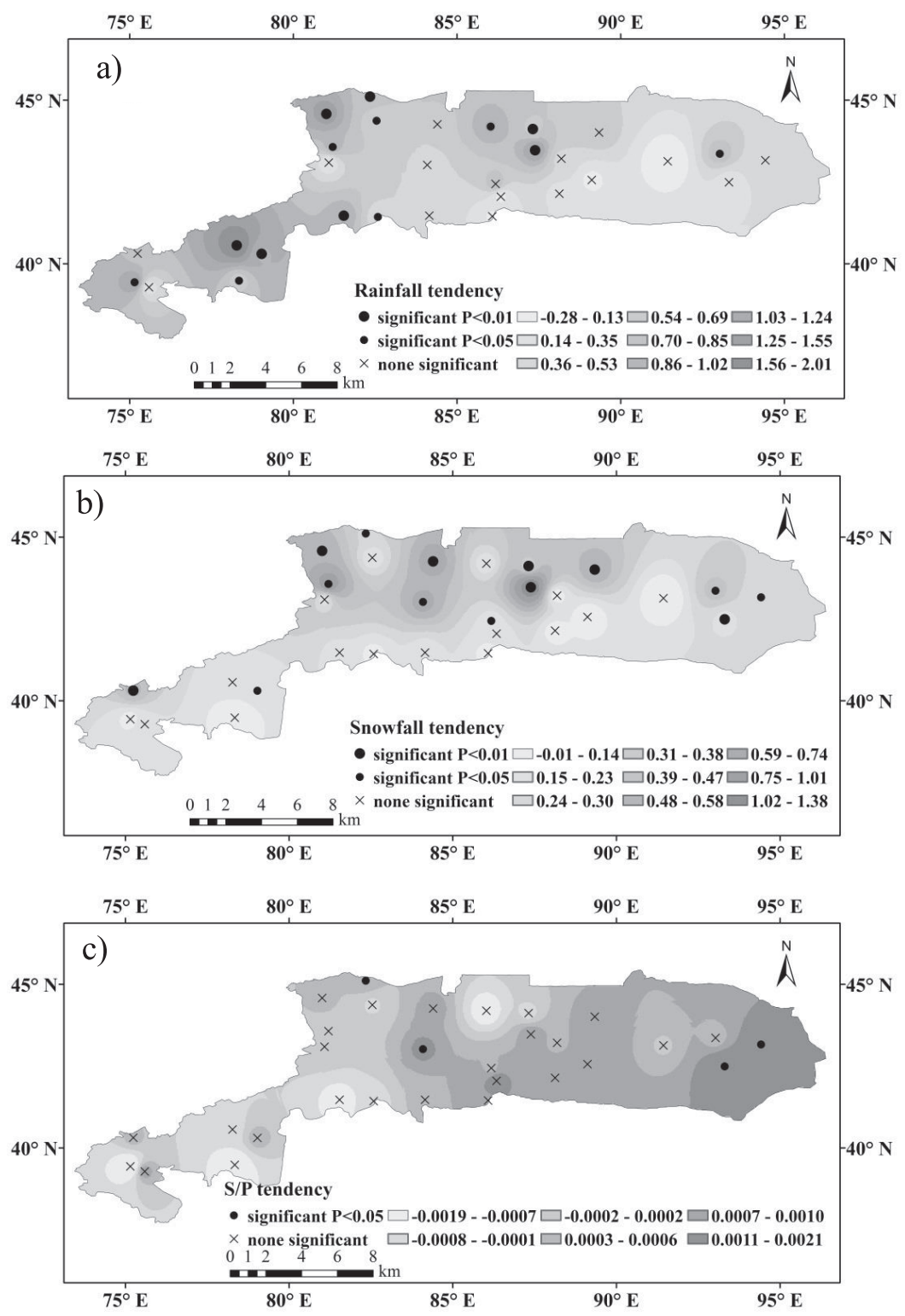

Fig. 8. Spatial distribution of rainfall, snowfall, and the ratio of snowfall to total precipitation $(\mathrm{S} / \mathrm{P})$ in the northern and southern slopes of Tianshan Mountains (a: rainfall, b: snowfall, c: S/P ratio) for the period 1961-2015.

and eastern parts recording a higher proportion of snow than the western part; however, this increase was not significant in $87 \%$ of the stations. Bayinbuluk along the northern slopes and Hami along the southern slopes recorded higher rates of increase in the ratio, whereas the rates were lower in Shihezi along the northern slopes and in Baicheng and Wuqia along the southern slopes.

The dominant periods for each of the two phases were calculated using wavelet analysis, and the periods were then interpolated on the ArcGIS platform (Fig. 9).

The dominant periods of rain and snow ranged from 8 to 30 years. The length of the period over which rainfall was dominant decreased from west to east in the northern slopes and from centre to east and to west in the southern slopes. The dominant period for the western part of the northern slopes and for the central part of the southern slopes ranged from approximately 18 to 30 years, whereas for the eastern parts of the northern slopes and for the eastern and western parts of the southern slopes, the period was shorter than 13 years (it was about 14 to 30 years in Turgart, Akeqi, and Wuqia in the western parts).

The lengths of the period over which snowfall was dominant were similar for the northern and the southern slopes, showing that the dominant period for the central part (20-30 years) was longer than that for the eastern and western parts (less than 19 years, although in Turgart, Korla, and Bachu it was 20-30 years). The spatial distribution of the dominant period confirmed the overall pattern described in Section Periodic variations in the precipitation phase. However, more research is required on the periodicity changes at 

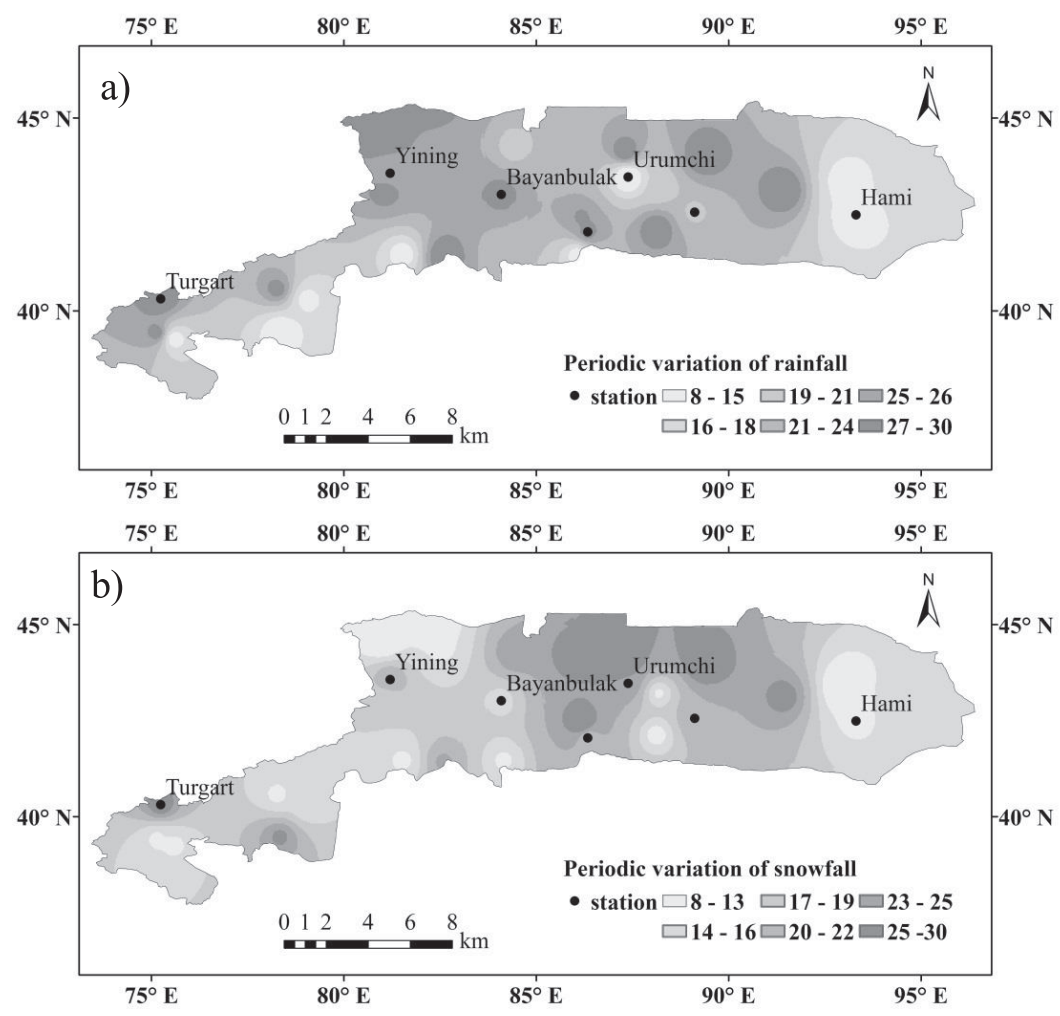

Fig. 9. Spatial distribution of dominant periods for rain and snow in northern and southern slopes of Tianshan Mountains (a: rainfall, b: snowfall) for the period 1961-2015.

each station along both slopes in order to find out how the spatial distribution of the two precipitation phases will change in the future.

\section{Conclusions}

The temporal and spatial variations in the two phases of precipitation (rain and snow) in the northern and southern slopes of the Tianshan Mountains were compared and analyzed based on 55-year-old data (1961-2015) of daily precipitation, temperature, and relative humidity. The results were as follows.

1) The rainfall and snowfall increased in both slopes, and the rate of increase itself also continued to increase. The rate of increase in rainfall in the southern slopes was slightly greater than that in the northern ones, whereas with snowfall the pattern was exactly opposite. The ratio of snow to total precipitation, however, decreased - the decrease in the contribution of snow to total precipitation was probably due to global warming.

2) The precipitation in the northern slopes was significantly higher than that in the southern ones. Except for Qijiaojing, which lies along a northern slope, both rainfall and snowfall increased along both slopes, although the rate of increase was not uniform, being higher in the east and lower in the west. However, the ratio of snowfall to total precipitation showed the opposite trend, with the contribution of snow to the total precipitation in the middle and eastern parts of the Tianshan Mountains being greater than that in the western ones.

3) The Mann-Kendall test, at a confidence level of 0.05 , showed that the mutation changes in rainfall and snowfall occurred in 1985 and 1986 in the northern slopes and in 1976 and 1990 in the southern ones. After the mutation, both rainfall and snowfall increased, the mutational difference in the case of rainfall in the southern slopes being greater than that in the northern ones. On the other hand, in the case of snowfall the pattern was the exact opposite: the mutational difference in the northern slopes was greater than that in the southern ones. The ratio of snow to total precipitation, however, showed no marked change over the entire period.

4) The dominant period of rainfall and snowfall in both northern and southern slopes was 8-30 years. Over the next 20-30 years, rainfall throughout the Tianshan Mountains and the snowfall in their northern slopes are likely to be above normal, whereas snowfall in the southern slopes is likely to be less than normal. Therefore, it is expected that the proportion of snowfall to total precipitation in the southern slopes will decrease further over the next 20 years, whereas further research is needed before any prediction can be made about the contribution of snowfall in the northern slopes. 


\section{Acknowledgements}

This work was supported by the Natural Foundation of China (51569027), the Science and Technology Special Projects of Xinjiang Uygur Autonomous Region (2016A03008-4) and the Tianshan Innovation Team Project (Y744261). The authors would like to thank the anonymous reviewers for suggesting improvements to the manuscript.

\section{Conflict of Interest}

The authors declare no conflict of interest.

\section{References}

1. YE H., COHEN J., RAWLINS M. Discrimination of solid from liquid precipitation over Northern Eurasia using surface atmospheric conditions. Journal of Hydrometeorology. 14 (4), 1345, 2013.

2. FEICCABRINO J., GRAFF W., LUNDBERG A., SANDSTRÖM N., GUSTAFSSON D. Meteorological knowledge useful for the improvement of snow rain separation in surface based models. Hydrology. 2 (4), 266, 2015.

3. LENDERINK G., FOWLER H.J. Hydroclimate: Understanding rainfall extremes. Nature Climate Change. 7 (6), 391, 2017.

4. WMO. Reducing and managing risks of disasters in a changing climate. WMO Bulletin. Volume 62 (Special Issue), 23, 2013.

5. TEDESCO M., DOHERTY S., FETTWEIS X., ALEXANDER P., JEYARATNAM J., STROEVE J. The darkening of the Greenland ice sheet, trends, drivers and projections (1981-2100). Cryosphere Discussions. 9 (5), $5595,2016$.

6. CANNON F., CARVALHO L.M.V., JONES C., BOOKHAGEN B. Multi-annual variations in winter westerly disturbance activity affecting the Himalaya. Climate Dynamics. 44 (1-2), 441, 2015.

7. COLLI M., RASMUSSEN R., THÉRIAULT J.M., LANZA L.G., BAKER C.B., KOCHENDORFER J. An improved trajectory model to evaluate the collection performance of snow gauges. Journal of Applied Meteorology \& Climatology. 54 (8), 1826, 2015.

8. MARKS D., WINSTRAL A., REBA M. An evaluation of methods for determining during-storm precipitation phase and the rain/snow transition elevation at the surface in a mountain basin. Advances in Water Resources. 55 (3), 98, 2013.

9. IPCC. Climate change 2014, impact, adaptation and vulnerability. Cambridge University Press, 2014.

10. WU Y., LIU S., YAN W., XIA J., XIANG W., WANG K., LUO Q., FU W., YUAN W. Climate change and consequences on the water cycle in the humid Xiangjiang River Basin, China. Stochastic Environmental Research \& Risk Assessment. 30 (1), 225, 2016.

11. BERGHUIJS W.R., WOODS R.A., HRACHOWITZ M.A. precipitation shift from snow towards rain leads to a decrease in streamflow. Nature Climate Change. Volume 4, 583, 2014.
12. LISI P.J., SCHINDLER D.E., CLINE T.J., SCHEUERELL M.D., WALSH P.B. Watershed geomorphology and snowmelt control stream thermal sensitivity to air temperature. Geophysical Research Letters. 42 (9), 3380, 2015.

13. CHEN Y.N., LI Z., FANG G.H., DENG H. Impact of climate change on water resources in the Tianshan Mountains, Central Asia. Journal of Geographical Sciences. 72 (1), 18, 2017.

14. KONG Y., PANG Z. Evaluating the sensitivity of glacier rivers to climate change based on hydrograph separation of discharge. Journal of hydrology. Volume 434, 121, 2012.

15. CHEN Y.N., LI Z., FAN H.T., WANG H.J., FANG G.H. Research progress on the impact of climate change on water resources in the arid region of Northwest China. Journal of Geographical Sciences. 69 (9), 1295, 2014.

16. BARNETT T.P., ADAM J.C., LETTENMAIER D.P. Potential impacts of a warming climate on water availability in snow dominated regions. Nature. Volume 438, 303, 2005.

17. YOU F.C., GUO L.X., SHI Y.S., ZENG J., CENTER H.C. Discrimination index of precipitation phase state and its verification in Beijing. Journal of Meteorology \& Environment, 29 (5), 49, 2013.

18. LEE S.M., HAN S.U., WON H.Y., HA J.C., LEE Y.H., LEE J.H., PARK J.C. A method for the discrimination of precipitation type using thickness and improved matsuo's scheme over South Korea. Atmosphere. 24 (2), 151, 2014.

19. DING B., YANG K., QIN J., WANG L., CHEN Y., HE X. The dependence of precipitation types on surface elevation and meteorological conditions and its parameterization. Journal of Hydrology. 513 (11), 154, 2014.

20. YU J., ZHU H., QIU X., CAO W. A method to determine winter precipitation type in Anhui. Meteorological Monthly. 43 (9), 1052, 2017 [In Chinese].

21. FERNÁNDEZ-GONZÁLEZ S., VALERO F., SÁNCHEZ J.L., GASCÓN E., LÓPEZ L., GARCÍA-ORTEGA E., MERINO A. Numerical simulations of snowfall events: Sensitivity analysis of physical parameterizations. Journal of Geophysical Research Atmospheres. 120 (19), 155, 2015.

22. WAYAND N.E., STIMBERIS J., ZAGRODNIK J.P., MASS C.F., LUNDQUIST J.D. Improving simulations of precipitation phase and snowpack at a site subject to cold air intrusions, Snoqualmie Pass, WA. Journal of Geophysical Research Atmospheres. 121 (17), 2017.

23. SUN C., YANG J., CHEN Y., LI X., YANG Y., ZHANG Y. Comparative study of streamflow components in two inland rivers in the Tianshan Mountains, northwest China. Environmental Earth Sciences. 75 (9), 1, 2016.

24. HU W.J., LIU H.L., WANG H., ZHAO W.Y. Analysis of the terrain effect on snow cover accumulating and melting in Tianshan Mountains. Journal of Glaciology and Geocryology. 38 (5), 1227, 2016.

25. TANG Z., WANG X., WANG J., WANG X., LI H., JIANG Z. Spatiotemporal variation of snow cover in Tianshan Mountains, Central Asia, based on cloud-free MODIS fractional snow cover product, 2001-2015. Remote Sensing. 9 (10), 1045, 2017.

26. SORG A., BOLCH T., STOFFEL M., SOLOMINA O., BENISTONET M. Climate change impacts on glaciers and runoff in TianShan (Central Asia). Nature Climate Change. 2 (10), 725, 2012. 
27. ZHANG Z.Y., HE X.L., LIU L., LI Z., WANG P. Spatial distribution of rainfall simulation and the cause analysis in China's Tianshan Mountains area. Advances in Water Science. 26 (4), 500, 2015.

28. ZHANG X., LI X., GAO P., QIAN L., TANG H. Separation of precipitation forms based on different methods in Tianshan Mountainous area, northwest China. Journal of Glaciology \& Geocryology. 39 (2), 235, 2017.

29. HU R.J. Natural geography of Tianshan Mountain in China. Beijing, China Environmental Science Press, 2004.

30. WEI F.Y. Statistical diagnosis and prediction technology of modern climate (Second Edition). Beijing, Meteorological Press. 37, 2007.

31. ZHAO G.J., HORMANN G., FOHRER N., ZHANG Z., ZHAI J. Streamflow trends and climate variability impacts in Poyang Lake Basin, China. Water Resources Management. 24 (4), 689, 2010.

32. MATTI B., DAHLKE H.E., LYON S.W. On the variability of cold region flooding. Journal of hydrology. Volume 534, 669, 2016.

33. JONES J.R., SCHWARTZ J.S., ELLIS K.N., HATHAWAY J.M., JAWDYE C.M. Temporal variability of precipitation in the upper Tennessee Valley. Journal of Hydrology Regional Studies. Volume 3, 125, 2015.

34. FROIDUROT S., ZIN I., HINGRAY B., GAUTHERON A. Sensitivity of precipitation phase over the Swiss Alps to different meteorological variables. J. hydrometeor. 15 (2), 685, 2014.

35. KOISTINEN J., SALTIKOFF E. Experience of customer products of accumulated snow, sleet and rain. In, Advanced weather radar systems, COST 75 Int. Seminar, Locarno. 397, 1998.

36. LIU Y P., BAI H Z., QIAN Z.G., YANG X., ZHANG L., DUAN H. Further analyses of obvious moistening in central Xinjiang in recent 20 years. Plateau Meteorology. 100 (5), 299, 2011.

37. XIE P., GU Y.L., ZHANG H.C., LIU X. Precipitation and drought characteristics in Xinjiang during 1961-2015. Arid Land Geography. 40 (2), 332, 2017.

38. GUO L., LI L. Variation of the proportion of precipitation occurring as snow in the Tian Shan Mountains, China. International Journal of Climatology. 35 (7), 1379, 2015.

39. ZHONG Y., WANG B., ZOU C.B., HU B.X., LIU Y., HAO Y. On the teleconnection patterns to precipitation in the eastern Tianshan Mountains, China. Climate Dynamics. 49 (9-10), 3123, 2017.

40. YAO J.Q., YANG Q., HU W.F. Characteristics analysis of water vapor contents around Tianshan Mountains and the relationships with climate factors. Scientia Geographica Sinica. 33 (7), 859, 2013. 